Universidad

BIBLIOTECA

Document downloaded from the institutional repository of the University of Alcala: http://dspace.uah.es/dspace/

This is the author's version of the work. It is posted here by permission of the AAAS for personal use, not for redistribution. The definitive version was published in:

Perino et al., 2019. Rewilding complex ecosystems. Science (New York, N.Y.), 364(6438), p.351- .

Available at http://dx.doi.org/10.1126/science.aav5570

(C) 2019 The Authors, some rights reserved; exclusive licensee American Association for the Advancement of Science
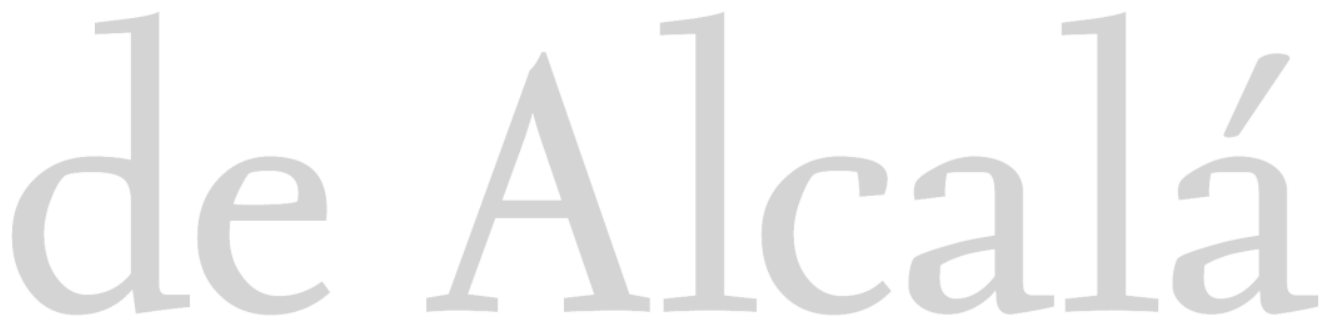

(Article begins on next page)

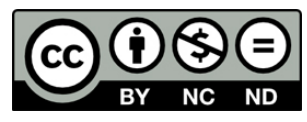

This work is licensed under a

Creative Commons Attribution-NonCommercial-NoDerivatives

4.0 International License. 


\section{Title: Rewilding complex ecosystems}

\section{Authors:}

Andrea Perino ${ }^{1,2 *}$, Henrique M. Pereira ${ }^{1,2^{*}}$, Laetitia M. Navarro ${ }^{1,2}$, Néstor Fernández ${ }^{1,2}$,

James M. Bullock ${ }^{3}$, Silvia Ceaușu ${ }^{4,5}$, Ainara Cortés-Avizanda ${ }^{6,7,8}$, Roel van Klink ${ }^{1}$, Tobias Kuemmerle ${ }^{9}$, Angela Lomba ${ }^{8}$, Guy Pe'er ${ }^{1,10,11}$, Tobias Plieninger ${ }^{12,13}$, José M. Rey Benayas ${ }^{14}$, Christopher Sandom ${ }^{15}$, Jens-Christian Svenning ${ }^{4,5}$, Helen Wheeler ${ }^{16,17,18,19}$

\section{Affiliations:}

${ }^{1}$ German Centre for Integrative Biodiversity Research (iDiv), Halle-Jena-Leipzig.

${ }^{2}$ Martin-Luther-University Halle-Wittenberg, Institut für Biologie.

${ }^{3}$ Centre for Ecology and Hydrology, Wallingford.

${ }^{4}$ Aarhus Universitet, Section for Ecoinformatics and Biodiversity, Department of Bioscience.

${ }^{5}$ Aarhus Universitet, Center for Biodiversity Dynamics in a Changing World (BIOCHANGE).

$15{ }^{6}$ Animal Ecology and Demography group, IMEDEA (CSIC-UIB), Balearic Islands (Mallorca), Spain

${ }^{7}$ Department of Conservation Biology, Estación Biológica de Doñana (CSIC), Seville, Spain

$20{ }^{8}$ CIBIO (Research Centre in Biodiversity and Genetic Resources) - InBIO (Reseach Network in Biodiversity and Evolutionary Biology). Campus Agrário de vairão, Rua Padre Armando Quintas, $n^{\circ}$ 7, 4485-661 Vairão, Vila do Conde, Portugal.

${ }^{9}$ Humboldt-University Berlin, Geography Department \& Integrative Research Institute for Transformations in Human-Environment Systems (IRI THESys). 
${ }^{10}$ Helmholtz-Zentrum für Umweltforschung UFZ; Leipzig University, Department Economics and Department Ecosystem Services.

${ }^{11}$ University of Leipzig

${ }^{12}$ University of Kassel, Faculty of Organic Agricultural Sciences.

${ }^{13}$ University of Göttingen, Department of Agricultural Economics and Rural Development.

${ }^{14}$ University of Alcalá, Department of Life Sciences.

${ }^{15}$ University of Sussex, School of Life Sciences.

${ }^{16}$ Anglia Ruskin University, Biology Department.

${ }^{17}$ Centre National de la Recherche Scientifique, Centre d'Écologie Fonctionnelle et Evolutive.

${ }^{18}$ UiT Norges arktiske universitet, Department of Arctic and Marine Biology.

${ }^{19}$ Université du Quebec à Rimouski.

*Correspondence to: andrea.perino@idiv.de and hpereira@idiv.de 


\section{Enhanced abstract}

Background: Rapid global change is creating fundamental challenges for the persistence of natural ecosystems and their biodiversity. Conservation through the protection of landscapes has had mixed success, and there is an increasing awareness that the long-term protection of biodiversity requires inclusion of flexible restoration along with protection. Rewilding is one such approach that has been both promoted and criticized in recent years. Proponents emphasize the potential of rewilding to tap opportunities for restoration while creating benefits for both ecosystems and societies. Critics discuss the lack of a consistent definition of rewilding and insufficient knowledge about its potential outcomes. Other criticisms arise from the mistaken notion that rewilding actions are planned without considering societal acceptability and benefits. Here, we present a framework for rewilding actions that can serve as a guideline for researchers and managers. The framework is applicable to a wide range of rewilding approaches ranging from passive to trophic rewilding and aims to promote beneficial interactions between society and nature.

\section{Advances:}

The concept of rewilding has evolved from its initial emphasis on protecting large, connected areas for large carnivore conservation to a process-oriented, dynamic approach. Based on concepts from resilience and complexity theory of social-ecological systems, we identify trophic complexity, stochastic disturbances, and dispersal as three critical components of dynamics of natural ecosystems. We propose that the restoration of these processes, and their interactions, can lead to increased self-sustainability of ecosystems and should be at the core of rewilding actions. Building 
on these concepts, we develop a framework to design and evaluate rewilding plans. Alongside ecological restoration goals, our framework emphasizes people's perceptions and experiences of wildness and the regulating and material contributions from restoring nature. These societal aspects are important outcomes and can be critical factors for the success of rewilding initiatives (Figure 0). We further identify current societal constraints on rewilding and suggest actions that can mitigate them.

Outlook: Rewilding challenges us to rethink the way we manage nature and it invites us to broaden our vision about how nature will respond to changes that society brings, both intentionally and unintentionally. The effects of rewilding actions will be particular for each ecosystem, and thus a deep understanding of the processes that shape ecosystems is critical to anticipate these effects and to take appropriate management actions. In addition, the decision whether a rewilding approach is desirable, should consider stakeholders' needs and expectations. To this end, structured restoration planning based on participatory processes involving researchers, managers and stakeholders,

15 including monitoring and adaptive management, can be used. With recent calls to designate 20202030 as the decade of ecological restoration, rewilding could be pushed to the forefront of discussions by policy and decision-makers on how to reach post-2020 biodiversity goals. 
Abstract: Rewilding has been both promoted and criticized in recent years. Benefits include flexibility to react to environmental change and the promotion of opportunities for society to reconnect with nature. Criticisms include the lack of a clear conceptualization of rewilding, insufficient knowledge about the possible outcomes, and the perception that rewilding excludes people from landscapes. Here, we present a framework for rewilding that addresses these criticisms. We suggest rewilding should target trophic complexity, natural disturbances, and dispersal, as interacting ecosystem processes that can improve ecosystem resilience and maintain biodiversity. We propose a structured approach to rewilding projects that include assessment of the contributions of nature to people and the social-ecological constraints on restoration.

One Sentence Summary: Rewilding can increase ecosystem resilience by promoting interactions among ecological processes, and aims to reconnect people with nature.

\section{Main Text:}

Shifting societal and environmental conditions, including land-use change and increasing demand for resources, are accelerating biodiversity loss and ecosystem degradation (1-4). The associated loss of many important ecological processes $(5,6)$ can decrease the complexity and resilience of ecosystems by hampering their capacity to recover from perturbations (7-9). Although responses

20 to the biodiversity crisis, especially the establishment of protected areas, have reduced biodiversity loss in some instances (10-12), reports of ineffective protected areas (13) and on-going declines of threatened species (14) show that conservation needs to go beyond current efforts $(15,16)$. 
A growing body of literature emphasizes the need for novel, process-oriented approaches to restoring ecosystems in our rapidly changing world $(4,17-19)$. Dynamic and process-oriented approaches focus on the adaptive capacity of ecosystems (4) and on the restoration of ecosystem processes promoting biodiversity, rather than aiming to maintain or restore particular ecosystem states characterized by predefined species compositions or particular bundles of ecosystem services. Such approaches recognize ecosystems as dynamic systems (20) whose future development cannot always be predicted $(21,22)$.

Rewilding is one such approach to restoration. It aims at restoring self-sustaining and complex ecosystems, with interlinked ecological processes that promote and support each other while 10 minimizing or gradually reducing human interventions (23-25). Rewilding also emphasizes the emotional experience and perception of wild nature and wild ecosystems without human intervention (20). Although conventional restoration projects often aim to minimize human intervention, many scientists and practitioners consider some level of management as critical to replace ecosystem processes that have been lost due to human activities or to maintain important

15 aspects of cultural landscapes (27). Such management often focuses on selected processes via precisely defined actions aiming at rather concrete end states (e.g., management of Satoyama landscapes in Japan (28)). Rewilding, on the contrary, recognizes and works with complexity and autonomy as ecosystem-inherent characteristics and acknowledges their dynamic, unpredictable nature (29).

20 Despite its potential to address pressing challenges in restoration, critics of rewilding have pointed out several shortcomings that have as yet hampered the application of rewilding principles. Criticism includes a lack of a consistent definition of rewilding (30) and insufficient knowledge about the possible outcomes of rewilding endeavors (31). In addition, concerns have been raised 
about rewilding activities being planned in a manner that excludes people from landscapes rather than designing rewilding projects with local support (32).

Here, we articulate a conceptual framework for rewilding projects that addresses the abovementioned criticisms. We start by briefly reviewing the history of the rewilding concept, from its initial emphasis on protecting large connected areas for carnivore conservation (33) to the diversity of rewilding concepts today (25). We propose a framework to design and evaluate rewilding plans that integrate the current diversity of rewilding approaches. Our framework draws on ecological theory to identify three interacting ecological processes that promote the self-organization of ecosystems and, therefore, should be the focus of rewilding actions. For each of these processes, we review ecological knowledge and identify rewilding actions that can assist the restoration of self-sustaining, resilient ecosystems. Importantly, these actions will vary depending on the societal context. Rewilding can happen spontaneously if humans withdraw from landscapes, for example after agricultural abandonment (34-36) or in areas that have become inhospitable due to armed conflict (37-39) or environmental catastrophes such as Chernobyl (40, 41). In other cases,

15 rewilding projects are driven by active choices about how societies want to experience nature (42) and to which degree society can accept an autonomy of natural processes. In these cases, the feasibility of rewilding projects also depends on the material, non-material and regulating contributions from nature that emerge from rewilding (Figure 2). We discuss how rewilding projects need to account for social-ecological dynamics, from the point of view of both addressing 20 people's preferences and the effects that humans have on ecosystems. Finally, we apply our framework to a set of on-going rewilding projects and illustrate how interactions among the key processes can be promoted to increase both ecosystem resilience and societal benefits. 


\section{A brief history of the rewilding concept}

Rewilding, as it was originally conceived 20 years ago (33), referred to " the scientific argument for restoring big wilderness based on the regulatory roles of large predators" (33) that could act as keystone species and maintain the resilience and diversity of terrestrial ecosystems through topdown control $(33,43)$. The protection and restoration of "large, strictly protected core reserves, connectivity and keystone species"(44) were the central characteristics of this first definition of rewilding. Although the conservation of large carnivores and their habitats is still an important aspect of rewilding $(25,45)$, the concept has evolved from this original idea to include a range of diverse approaches (25). Trophic rewilding, perhaps the closest to the original concept, advocates the reintroduction of missing keystone species, such as large carnivores and large herbivores. Trophic rewilding often advocates the use of functional replacements, i.e. the introduction of nonnative species as ecological proxies for species that became extinct centuries or millennia ago ( 25 , 32, 45). A particular type of trophic rewilding is Pleistocene rewilding, which aims at the restoration of ecosystems that include and are shaped by populations of megafauna extirpated since

15 the Late Pleistocene, taking a long-term evolutionary perspective on ecosystems (45). In contrast, ecological or passive rewilding emphasizes the passive management of ecological succession in abandoned landscapes. Passive rewilding actions include the creation of no-hunting areas, lowintervention forestry management, set-aside agricultural land, the removal of dispersal barriers, or the restoration of natural flood regimes $(22,25,34)$.

20 The ecosystem features that rewilding aims to restore are characteristic of wilderness areas (46, 47), but importantly, they are not restricted to those. Instead we refer to wildness, which is the autonomy of natural processes $(47,48)$ that can occur in a variety of settings and across spatial scales. The restoration of wildness, rather than wilderness, is thus the goal of rewilding. 
Broadening the original definition of rewilding and articulating the restoration of wildness rather than wilderness as its central goal makes rewilding applicable across spatial scales and adaptable to a wide range of societal and landscape contexts, from urban green spaces to abandoned agricultural landscapes (29).

\section{A theoretical framework for rewilding}

In many ecosystems, complexity and resilience are maintained by trophic complexity, natural disturbances, and dispersal $(49,50)$ (Figure 1). Human activities often lead to degradation in one or more of these ecological processes. Rewilding aims to restore these three ecological processes

10 to foster complex and self-organizing ecosystems that require minimum human management in the long run (51). If missing or degraded ecosystem processes are not expected to recover (on policy relevant time scales) without assistance, rewilding may encompass initial interventions, sometimes followed by continuous minimal management. In the following, we explain each of the processes in detail, elaborate how interactions among them can promote ecosystem resilience, and

15 illustrate how rewilding can be used to restore and promote such interactions.

\section{Trophic complexity}

Species at higher trophic levels are often highly connected and functionally important to ecosystems (Figure 1) (52). Large-bodied herbivores exert strong influences on the diversity and 20 abundance of other taxa such as birds, small mammals, insects $(53,54)$ and plants $(55,56)$. These effects occur through direct pathways, such as the provisioning of dung and carrion (57) or facilitation of dispersal $(55,56)$, but also through the modification of the physical environment by grazing and trampling, or the building of dams by beavers $(54,58)$. Large carnivores can, through 
predation, affect population sizes and behavior of herbivores and create spatio-temporal heterogeneity in these processes. In the absence of top-down control by carnivores, high densities of large herbivores can have detrimental effects on the abundance and diversity of other species groups $(53,54)$.

Humans cause changes in species composition and alter species interactions through hunting, harvesting or planting selected species in agriculture and forestry (Figure 1a). Especially large vertebrates are susceptible to human-driven defaunation due to their body size, long reproductive cycles, and high metabolic demands leading to the need for large foraging ranges (59-63). Thus, even where large vertebrates are still present in human-dominated landscapes, they might not be able to exert the top-down control they have in wild ecosystems due to their reduced densities (64, 65). Selective defaunation of top predators and large herbivores can result in trophic cascading effects and higher susceptibility of ecosystems to collapse $(52,66)$.

Rewilding can enhance trophic complexity through a variety of actions that depend on the characteristics of the ecosystem. Passive rewilding measures can, for example include the creation

15 of no-hunting areas. Where spontaneous recolonization is unlikely, the restoration of trophic complexity might also be achieved by translocating species. Introductions of ecological replacements can be an option if species have gone extinct globally (45). However, such replacements can entail unforeseeable uncertainties and ecological risks and should be assessed with caution (25). Rewilding can also be supported by activities to promote coexistence between 20 people and wildlife, e.g., through compensation schemes for crop- or livestock damage (67, 68). 


\section{$\underline{\text { Stochastic disturbances }}$}

Natural disturbances often occur in a stochastic manner at different locations, magnitudes and frequencies, enhancing spatial and temporal heterogeneity in ecosystems (49). They can trigger reorganization and reconfiguration of ecosystems (69) and can lead to increased ecosystem complexity. They promote co-existence as often there is a trade-off in species' competitive abilities and resilience to events like fires, floods or pest outbreaks (69). Species that are able to survive disturbances act as biological legacies that promote recovery and reorganization (e.g., seed banks or small mammals surviving a fire) (49).

In human-dominated landscapes, natural disturbances are often suppressed (e.g., fire suppression or flood regulation) or altered in their magnitude and frequency (Figure 1a), which may lead to even larger and potentially devastating disturbance events (e.g., large wildfires rather than smaller and more frequent ones). Instead, stochastic disturbances are replaced by predictable and constant disturbances (e.g., use of fertilizers and irrigation to maintain constant inputs to ecosystems, or annual soil mobilization to weed out competing species (49)). These deterministic disturbances

15 often act in the same place over a long period of time without a chance for the affected ecosystem to recover and reorganize (69) and may lead to the loss of sensitive species (1). Moreover, human efforts to repair damage after natural disturbance events can remove biological legacies $(49,69)$ and lead to additional perturbations that hinder natural regeneration and reorganization processes (70). For example, salvage logging to remove dead trees after wind throw or pest outbreaks often

20 removes important resources and habitats for saproxylic beetles or cavity-nesting species (71).

Rewilding actions aim to release ecosystems from continued and controlled anthropogenic disturbances to allow for natural variability and sources of stochasticity (72) (Figure 1b). Mowing of grassland can be reduced or replaced by natural grazing. Dams can be removed or their 
management modified to restore natural flood regimes (73). Logging can be replaced by allowing natural fire and pest regimes.

\section{Dispersal}

5 Populations depend on dispersal among habitats to avoid overcrowding (74), intraspecific competition and loss of genetic diversity (75). The exchange of individuals from different populations can increase gene flow, mitigate inbreeding and hence lead to more viable populations (76). Habitat degradation or anthropogenic dispersal barriers reduce habitat connectivity and dispersal ability (Figure 1a).

10 A rewilding approach includes the improvement of connectivity within and among ecosystems to promote dispersal. While connectivity efforts often focus on corridors alone, a multi-scale approach should seek to identify and link opportunities, ranging from local features such as hedgerows to support birds or insects (77), to large-scale corridors which allow recolonization by large mammals over long distances. Connectivity can also be improved by removing or increasing

15 the permeability of dispersal barriers (Figure 1b) such as roads, dams or fences. The permeability of unsuitable habitat, particularly homogeneous agricultural areas, can be improved by the introduction of natural landscape elements (78).

\section{$\underline{\text { Integrating across ecological processes }}$}

20 The three ecological processes can influence and promote one another (Figure 1). Disturbances can, for example, promote habitat heterogeneity and increase resource availability for less competitive species and may therefore lead to an increase in species diversity (79). High dispersal among habitats aids recovery of ecosystems after (major) disturbance events by allowing 
recolonization and recovery of populations of affected species (Figure 1b). Large vertebrates present in complex ecosystems often act as dispersal agents for plants $(55,56)$, and can introduce stochasticity into a system, e.g., through predation or grazing (80). Therefore, the restoration of one of these processes may positively influence the functionality levels of the two other processes

5 (Figure 1b). Interactions among the processes can increase ecosystem resilience by jointly promoting, for example, functional redundancy or recolonization.

Rewilding efforts can be assessed by representing ecosystems in their degraded and restored states in a three-dimensional, pyramid-shaped space where each axis corresponds to an ecological process, and the faces represent the interaction between processes (Figure 2). During the 10 restoration of a process, the respective vertice of the pyramid moves further away from the origin and the volume of the pyramid increases. The difference in volume between the restored and degraded ecosystem is thus a proxy for the effect of rewilding on the resilience of the ecosystem. Note that because the processes interact, it is expected that restoring only one dimension but leaving the other two unaddressed often corresponds to a smaller improvement than restoring the

15 three dimensions simultaneously, e.g., the change in the volume of the pyramid is very small when one of the axis is fully restored but the other two axes remain highly degraded.

\section{Rewilding as a societal choice}

Ecosystems cannot be assessed separately from human societies (81). All areas that are candidates

20 for rewilding are influenced by people and/or have a history of use. Consequently, any rewilding project can affect local livelihoods and wellbeing. Societal changes can influence ecosystems in positive or negative ways and vice versa, and the trajectories of ecosystems are often defined by human decisions that focus on the delivery of certain resources and ecosystem services $(68,82)$. 
Considering and managing for interactions between ecosystems and people while assessing and communicating the benefits of rewilding for society (Figure 2) can incentivize actions that benefit both ecosystems and society (68) and, therefore, increase the acceptance and success of rewilding endeavors.

5 The restoration of the three ecosystem processes can positively impact people's lives in various ways. Rewilding plays an important role for non-material contributions of nature and relational values of biodiversity (83). A growing body of literature concludes that exposure to green or natural spaces can reduce stress levels, increase positive emotions and cognitive function, encourage physical activity, and facilitate social cohesion in humans (84-86). Especially wilderness experiences provide an opportunity for eco-therapy to promote psychological resilience in children and adolescents (87), and personal transformation and self-fulfillment in adults (88). Moreover, the satisfaction that certain people perceive if species or ecosystems exist and thrive $(89,90)$ can reach societies in great geographical distance to an actual rewilding site. The presence of charismatic or symbolic species or landscapes can inspire spiritual, artistic and technological 15 development (42). Far-ranging and migrating species travelling on dispersal pathways may motivate nature-based activities such as birdwatching (42). Being able to witness natural processes associated with childhood experiences, like the migration of swallows or cranes, can promote a sense of place and rootedness and be the basis for narratives, rituals and celebrations that form the core of the cultural identity of a place (42).

20 Economic benefits of rewilding may arise from opportunities for nature-based economies and alternative sources of income based on non-material contributions from nature (e.g., recreational activities $(42,91,92))$. Furthermore, natural disturbance events can trigger innovation and change in social-ecological systems (93). Rewilding promotes other regulating services and nature-based 
solutions such as regulation of climate, air quality, pollination and dispersal of seeds $(42,94)$. Improved dispersal potential and trophic complexity may prevent the depletion of material contributions from nature (42) such as economically relevant natural resources (e.g., wildlife game), not only in the areas undergoing rewilding but also in surrounding areas.

However, rewilding can also have undesired consequences for people. Natural disturbances like fires or floods may threaten humans and human infrastructure (95). Human-wildlife conflicts, for example crops damaged by large herbivores or livestock killed by large predators (96), are becoming more frequent and more severe where these animals are reintroduced or their populations recover (97). Additionally, concerns over the loss of traditional, cultural landscapes,

10 including their unique natural and cultural heritage, are growing in Europe and other regions (91, 98, 99). Particular unease has been expressed regarding impacts on farmland biodiversity and on cultural ecosystem services, for example aesthetic values (100), sense of place (101), and a general "erasure" of human history and involvement with the land and its flora and fauna (32).

In sum, the relationship of people with wildness in nature is and has always been characterized by

15 sets of paradoxes (102). These range from contradictory views of wildness in nature ascribed to prehistoric peoples as a "constant threat to [human] life and livelihood" vs. the "primary source of life and livelihood" to contemporary, contradictory perceptions as "a potentially dangerous, alienating and challenging place" vs. "a potentially peaceful refuge to relax and conveniently enjoy" (102). This range of emotions highlights that well-planned rewilding projects that mitigate

20 possible conflicts have higher potential to maximize the positive experiences and beneficial contributions from nature. 


\section{Science \\ MAAAS}

\section{Submitted Manuscript: Confidential}

\section{Applying the framework}

A structured and participatory approach to rewilding is important to ensure that all stakeholders have a clear understanding of the goals, the management options, the desirable outcomes, and the associated risks (103). The first step of a rewilding project should be an analysis of the ecological

5 status of the focus area, by identifying missing and/or degraded components. Paleo-ecological data, for example on past vegetation change, megafauna presence, or fire dynamics, as well as past information on land-use histories should be considered in such analyses (4).

In the second step, managers should assess the ecological viability of different management options and potential synergies among those. Together with key stakeholders (e.g.,

10 conservationists, farmers, hunters, general public), managers should identify social-ecological constraints (e.g., infrastructure hindering dispersal, emerging human-wildlife conflicts or risks associated with the restoration of natural disturbances), and evaluate benefits and disadvantages associated with the rewilding intervention.

The third step is the implementation of the rewilding actions using an adaptive management

15 approach. This includes the monitoring of the different interventions, ideally using a before-aftercontrol-impact (BACI) approach (104), that considers both the ecological and the societal outcomes. Results of this monitoring may lead to adjustments in ongoing rewilding interventions or raise the need for further management actions and decisions. The implementation phase should be accompanied by a communication strategy that involves affected communities in decisions, and 20 outreach activities that inform the wider public about the outcomes of rewilding. These should be offered via a broad array of opportunities for nature experiences (e.g., guided tours through the rewilding area, nature education tools, opportunities for leisure activities). Additionally, managers 
may seek to develop opportunities for sustainable business opportunities to increase the acceptance of rewilding among stakeholders.

Our stepwise approach can also be applied for passive rewilding projects. In that case, there is no deliberate decision to initiate a project, but instead managers can take advantage of ongoing socialecological dynamics (e.g., farmland abandonment). If this opportunity is identified, the first step will involve an assessment of the already ongoing passive rewilding dynamics, associated risks and benefits, and potential impediments to those dynamics. The second step will focus on identifying options to support those dynamics and mitigate threats. This will often involve the consolidation of ongoing non-intervention (e.g., establishment of no-hunting arrangements, or

10 protected areas), or the mitigation of emerging conflicts. Similar to active rewilding projects, the third step involves adaptive management, monitoring and outreach activities.

We now demonstrate the stepwise application of our framework with four rewilding case studies, spanning a range of scales, ecosystem types, and degrees of intervention (Figure 2). As it will become apparent, the development of a rewilding project is rarely a linear process. Due to the

15 adaptive nature of our approach, some of the steps will be carried out repeatedly and/or in parallel.

\section{Restoration of the natural flood regime in the Leipziger Auwald City Forest, Germany}

The Leipziger Auwald is an alluvial forest surrounding and crossing the city of Leipzig in Germany. Since the middle of the $19^{\text {th }}$ Century, flood suppression and changes have led to a well20 documented change in tree community composition with increasing dominance of sycamore (Acer pseudoplatanus), Norway maple (Acer platanoides) and common ash (Fraxinus excelsior), mainly at the expense of hornbeam (Carpinus betulus) and oak (Quercus robur) (105). In its current state, 
connectivity between the waterbodies in the Auwald is severely diminished, and active management is necessary to restore this process (Figure 2a).

After identifying the flood disturbance as a major missing component of this ecosystem, city managers have started yearly experimental flooding of a pilot area in the early 1990s (106). Results

5 of concomitant monitoring confirmed the effectiveness and suitability of this management action.

Flooding lead to an increase of flood-tolerant species like oak and hornbeam and a decrease or local extinction of some plant species that are intolerant to flooding but had become dominant after flooding had been supressed (e.g., sycamore and Norway maple) (106). At the same time, colonization by moisture-tolerant slug species and (re-)colonization by several ground beetle

10 species associated with alluvial forest systems was observed (106). The findings of this long-term experiment inform the implementation phase where the natural flood regime is restored in several drained branches of the river (Lebendige Luppe project) (73) (Figure 2a).

The implementation phase is accompanied by an extensive outreach strategy that offers several opportunities for the public to engage with the ecosystem in the Auwald. It provides multimedia 15 teaching material to support environmental education, and tools for interactive experiments (e.g., magnifying glasses, landing nets and maps) that allow children to learn about the ecology and topography of the alluvial forest and explore its flora and fauna. A local conservation NGO organizes excursions to inform about ongoing activities and regular public discussion forums offer the opportunity to engage actively in the project. Two concomitant research programs evaluate the

20 ecological outcomes of the project and monitor and evaluate the acceptance and perception of natural processes in the Auwald, respectively (107). 


\section{Science}

Submitted Manuscript: Confidential

AIAAAS

\section{$\underline{\text { Non-intervention policy in the Swiss National Park }}$}

Established in 1914, the Swiss National Park is the oldest National Park in Europe and the largest protected area in Switzerland (108). Already in 1909, its founders, both botanists and naturalists, who were concerned with the widespread development of touristic infrastructure threatening the region's unique flora and fauna, identified the region around the Pass dal Fuorn as a suitable target area owing to its remoteness and species richness (108).

Making space for natural processes and conducting research on how these develop are central missions of the park management (108). The establishment of the park and management decisions were advised by cartographers and naturalists who had extensive knowledge about the area and its

10 ecosystems (109). The protection status of the area was secured by a lease agreement that was negotiated with the local municipalities, and was financed through the foundation of the Swiss Federation of Nature Conservation.

Since its establishment, the National Park has been subject to a strict non-management approach and has been fully protected from human activities such as hunting, agriculture or forestry. Trophic

15 complexity was promoted through targeted reintroductions of ibex (Capra ibex) in 1920, 1923 and 1926, and bearded vultures (Gypaetus barbatus; 1991 - 2007) (110). Natural disturbances are not managed and dispersal potential is high for most species (Figure $2 \mathrm{~b}$ ). The development of the ecosystem has been monitored continuously, and many of the monitoring schemes have been in place for decades (109). Conflicts with local communities were mitigated via selected active

20 management measures. For example, public discontent over sapling damage caused by red deer (Cervus elaphus) was mitigated by organizing hunting events outside the borders of the park (109). The non-management approach has resulted in the recovery of large populations of red deer, 


\section{Science \\ AIAAAS}

\section{Submitted Manuscript: Confidential}

chamois (Rupicapra rupicapra), ibex, and roe deer(Capreolus capreolus), species that were nearly extinct or very rare in Switzerland when the park was established (111). The increased red deer density has resulted in higher plant species richness in subalpine grassland (112). Additionally, wolves (Canis lupus) and brown bears (Ursus arctos) have recently been sighted, suggesting the

5 imminent recolonization of the area by large predators. Socio-economic studies show that the park attracts around 150,000 visitors per year, contributing significantly to the economic prosperity of the region $(109,113,114)$.

10 Restoring ecological interactions in the Tijuca National Park, Rio de Janeiro City, Brazil

The Atlantic Forest of Brazil is a globally important biodiversity hotspot. However, most of the protected areas containing Atlantic Forest remnants have been defaunated (115). One of these remnants is the Tijuca National Park in Rio de Janeiro. During the $17^{\text {th }}$ and $18^{\text {th }}$ century, deforestation for agricultural purposes and hunting pressure have led to severe losses of its native

15 fauna. Since the forest is completely surrounded by urban infrastructure, the animal species community could not fully recover after the area was reforested in the $19^{\text {th }}$ century (116), and dispersal of mammal species to other ecosystems is still inhibited.

The REFAUNA project was established in 2012 to restore the mammal community via gradual reintroductions of species that have disappeared from the Atlantic Forest (116). Tijuca was 20 considered suitable for first reintroductions because its relatively small size and its location in an urban area would allow for easy monitoring and control of the released animals (116). Researchers identified two native, locally extinct candidate species, the red-humped agouti (Dasyprocta leporina) and the howler monkey (Alouatta guariba), both of which were expected to promote 


\section{Science}

MAAAS

\section{Submitted Manuscript: Confidential}

ecological interactions in the National Park. Agoutis are important dispersers of large seeded plants (117) and increase seed survival by transporting them to locations with lower densities of conspecific tree species. Howler monkeys influence dung beetle abundances and the decomposition of howler dung by the beetles can enhance nutrient cycling and soil fertilization (118).

Concomitant monitoring revealed that the presence of agoutis and howler monkeys enhanced ecological interactions in the park. Agoutis broadened their diet and improved the dispersal and germination success of several large-seeded plants. By interacting with the dung-beetle community, howler monkeys promoted the dispersal of large seeds and with likely positive effects

10 on forest regeneration (116) (Figure 2c). Although Tijuca is Brazil's most popular National Park (119), there is little emotional connection between the park and people living in adjacent communities (120). To improve the linkage between the park and local communities, the management has installed a park council where representatives of governmental institutions, nongovernmental organizations and of the private sector, aim to reach satisfactory management

15 decisions for all stakeholders (121). A community based, cooperative project has trained locals as tourist guides and offers tours through the park and a neighboring favela. Additionally, the cooperation runs a restaurant that offers products of local cuisine prepared with products growing in the forest and in community gardens $(122,123)$.

\section{Ecosystem and wildlife recovery in the Chernobyl exclusion zone}

The meltdown of the nuclear reactor in Chernobyl on 26th April 1986 resulted in massive contamination, especially in the immediate surrounding of the reactor (124-126). The evacuation of the entire local population within a $30 \mathrm{~km}$ exclusion zone around the reactor, and the most strongly contaminated areas outside this zone resulted in the abandonment of about $1,400 \mathrm{~km}^{2}$ of 


\section{Science \\ AIAAAS}

\section{Submitted Manuscript: Confidential}

agricultural land $(40,41)$. The breakdown of the Soviet Union, with widespread outmigration and an additional $36 \%$ of all farmland abandoned in Belarus and Ukraine, further lowered human pressure in the surrounding of the Chernobyl site (41).

Two years after the meltdown, the Belarusian part of the exclusion zone and adjacent areas were turned into the strictly protected $1,300 \mathrm{~km}^{2}$ Polesie State Radioecological Reserve. In 1993, the reserve was extended by $850 \mathrm{~km}^{2}$, making it the largest nature reserve in Belarus (127). Management of the exclusion zone on both sides of the border has since followed a paradigm of minimum to no intervention. Targeted reintroductions of European bison (Bison bonasus) in the Polesie State Radioecological Reserve and of Przewalski's horses (Equus ferus przewalskii) to the

10 Ukrainian exclusion zone to restore trophic interactions in the Chernobyl area were exceptions to this passive approach. Recognizing the growing ecological and conservation value of the Chernobyl area, the Ukrainian government has recently established the 2,300 $\mathrm{km}^{2}$ Chornobyl Radiation and Ecological Biosphere Reserve in 2016 (128), establishing an almost 500km², contiguous rewilding area in the heart of Eastern Europe. Management activities in the biosphere

15 reserve aim at the recovery of biodiversity and ecosystem resilience and include monitoring of the ecological, medical and radiation status of the area as well as educational activities (128).

The region now harbors the entire portfolio of extant European large carnivores (i.e., wolf, lynx (Lynx lynx), and brown bear), large herbivores (European bison, wild horse, moose (Alces alces), red deer, roe deer, and wild boar (Sus scrofa), a rich meso-predator community (e.g., European 20 badger (Meles meles), raccoon dog (Nyctereutes procyonoides), red fox (Vulpes vulpes)) and key ecosystem engineers, such as the Eurasian beaver. The Chernobyl exclusion zone is the only area where these species interact in sizeable numbers with one another in a large wilderness complex 
and can thus be considered one of the most iconic natural experiments on rewilding in recent history.

\section{The way forward}

Rewilding directly targets restoring ecological functions instead of particular biodiversity compositional states. Therefore, the effects of rewilding may be indirect and unexpected. Consequently, the development of sound rewilding plans requires a deep understanding of interacting ecosystem processes leading to resilience, and of the socio-economic context in which rewilding takes place. Interdisciplinary training of scientists and practitioners is required to develop such understanding. Moreover, objective, evidence-based assessments of rewilding initiatives are needed to make rewilding projects fully accountable to funders, the public and the research community. A recently proposed method to assess progress of rewilding projects using a combination of expert-opinion and monitoring data (129) is a step towards this goal.

Unfortunately, current landscape management and conservation policies do not provide sufficient opportunities for rewilding to be implemented on a broader scale. For instance, the common 15 agricultural policy (CAP) incentivizes agricultural activities in low production areas, impeding opportunities for rewilding in such areas (130). Restoration policies often focus on the safeguarding of current or historical conditions (130) and the protection of certain species and habitats $(24,130,131)$. Therefore, the successful contribution of rewilding to national and international biodiversity goals depends on policy changes that shift the conservation focus towards restoring the ecological processes identified in our framework (131).

Discussions on post-2020 biodiversity strategies by the signatory countries of the Convention on Biological Diversity (CBD) are currently being initiated, and several parties support El Salvador's proposal to declare the next decade a "decade of restoration" (132). We believe that rewilding 
provides one of the possible pathways towards the vision where "By 2050 biodiversity is valued, conserved, restored and wisely used, maintaining ecosystem services, sustaining a healthy planet and delivering benefits essential for all people" (133). Perhaps innovative policy changes favoring rewilding can add to the current momentum for novel approaches to restoration $(19,134)$. For instance, Aichi Target 15, which aimed at restoring 15\% of degraded ecosystems by 2020 , could be revised to recognize rewilding as a major approach to ecological restoration. An ambitious positive target of increasing wildness across the globe by 2030 could be a truly inspiring goal, infusing new energy and public support into global biodiversity policies.

\section{References and Notes:}

1. R. Dirzo, P. H. Raven, Global state of biodiversity and loss. Annu. Rev. Environ. Resour. 28, 137-167 (2003).

2. "Millenium Ecosystem Assessment. Ecosystems and human well-being: Biodiversity synthesis." (World Resources Institute, Washington D.C., 2005).

3. J. A. Foley, Global consequences of land use. Science. 309, 570-574 (2005).

4. A. D. Barnosky et al., Merging paleobiology with conservation biology to guide the future of terrestrial ecosystems. Science. 355 (2017), doi:10.1126/science.aah4787.

\section{$20 \quad$ (2012).}

6. N. Pettorelli et al., Satellite remote sensing of ecosystem functions: opportunities, challenges and way forward. Remote Sens. Ecol. Conserv. (2017), doi:10.1002/rse2.59.

7. C. S. Holling, Resilience and stability of ecological systems. Annu. Rev. Ecol. Syst. 4, 123 (1973).

25 8. M. Scheffer, S. Carpenter, J. A. Foley, C. Folke, B. Walker, Catastrophic shifts in ecosystems. Nature. 413, 591-596 (2001).

9. T. H. Oliver et al., Declining resilience of ecosystem functions under biodiversity loss. Nat. Commun. 6 (2015), doi:10.1038/ncomms10122.

10. S. Chape, J. Harrison, M. Spalding, I. Lysenko, Measuring the extent and effectiveness of 30 protected areas as an indicator for meeting global biodiversity targets. Philos. Trans. R. Soc. B Biol. Sci. 360, 443-455 (2005).

11. C. L. Gray et al., Local biodiversity is higher inside than outside terrestrial protected areas worldwide. Nat. Commun. 7 (2016), doi:10.1038/ncomms12306.

12. R. M. Pringle, Upgrading protected areas to conserve wild biodiversity. Nature. 546, 9199 (2017). 
13. W. F. Laurance et al., Averting biodiversity collapse in tropical forest protected areas. Nature. 489, 290-294 (2012).

14. C. A. Hallmann et al., More than 75 percent decline over 27 years in total flying insect biomass in protected areas. PLOS ONE. 12, e0185809 (2017). (2004).

16. S. L. Pimm, P. Raven, Extinction by numbers: Biodiversity. Nature. 403, 843-845 (2000).

17. L. Thomas, J. Middleton, Guidelines for management planning of protected areas (IUCN, Cambridge, 2003), vol. 10 of Best practice protected area guidelines.

18. A. Valiente-Banuet et al., Beyond species loss: The extinction of ecological interactions in a changing world. Funct. Ecol. 29, 299-307 (2015).

19. E. S. Higgs et al., Keep ecological restoration open and flexible. Nat. Ecol. Evol. (2018), doi:10.1038/s41559-018-0483-9.

15 20. D. Lindenmayer et al., A checklist for ecological management of landscapes for conservation. Ecol. Lett. 0, 071010211025003-??? (2007).

21. R. T. Corlett, Restoration, reintroduction, and rewilding in a changing world. Trends Ecol. Evol. 31, 453-462 (2016).

22. B. Cantrell, L. J. Martin, E. C. Ellis, Designing autonomy: Opportunities for new wildness in the Anthropocene. Trends Ecol. Evol. 32, 156-166 (2017).

23. J. Lorimer et al., Rewilding: Science, practice, and politics. Annu. Rev. Environ. Resour. 40, 39-62 (2015).

24. P. Jepson, A rewilding agenda for Europe: Creating a network of experimental reserves. Ecography. 39 (2016), doi:10.1111/ecog.01602.

25 25. N. Fernández, L. M. Navarro, H. M. Pereira, Rewilding: A Call for boosting ecological complexity in conservation. Conserv. Lett. 10, 276-278 (2017).

26. G. Monbiot, Feral: Searching for Enchantment on the Frontiers of Rewilding. (Penguin UK, 2013).

27. C. Queiroz, R. Beilin, C. Folke, R. Lindborg, Farmland abandonment: Threat or opportunity for biodiversity conservation - a global review. Front. Ecol. Environ. 12, 288-296 (2014).

28. K. Katoh, S. Sakai, T. Takahashi, Factors maintaining species diversity in satoyama, a traditional agricultural landscape of Japan. Biol. Conserv. 142, 1930-1936 (2009).

29. J. Prior, E. Brady, Environmental aesthetics and rewilding. Environ. Values. 26, 31-51 (2017).

30. D. Nogués-Bravo, D. Simberloff, C. Rahbek, N. J. Sanders, Rewilding is the new Pandora's box in conservation. Curr. Biol. 26, R87-R91 (2016).

31. D. R. Rubenstein, D. I. Rubenstein, From Pleistocene to trophic rewilding: A wolf in sheep's clothing. Proc. Natl. Acad. Sci. 113, E1-E1 (2016).

40 32. D. Jørgensen, Rethinking rewilding. Geoforum. 65, 482-488 (2015).

33. M. E. Soulé, R. Noss, Rewilding and biodiversity: Complementary goals for continental conservation. Wild Earth, 18-28 (1998).

34. L. M. Navarro, H. M. Pereira, Rewilding abandoned landscapes in Europe. Ecosystems. 15, 900-912 (2012).

45 35. S. Estel et al., Mapping farmland abandonment and recultivation across Europe using MODIS NDVI time series. Remote Sens. Environ. 163, 312-325 (2015). 
36. P. Meyfroidt, F. Schierhorn, A. V. Prishchepov, D. Müller, T. Kuemmerle, Drivers, constraints and trade-offs associated with recultivating abandoned cropland in Russia, Ukraine and Kazakhstan. Glob. Environ. Change. 37, 1-15 (2016).

37. T. Hanson, Biodiversity conservation and armed conflict: a warfare ecology perspective: Conservation and conflict. Ann. N. Y. Acad. Sci. 1429, 50-65 (2018).

38. M. Baumann, V. C. Radeloff, V. Avedian, T. Kuemmerle, Land-use change in the Caucasus during and after the Nagorno-Karabakh conflict. Reg. Environ. Change. 15, 17031716 (2015).

39. M. Baumann, T. Kuemmerle, The impacts of warfare and armed conflict on land systems. J. Land Use Sci. 11, 672-688 (2016).

40. T. G. Deryabina et al., Long-term census data reveal abundant wildlife populations at Chernobyl. Curr. Biol. 25, R824-R826 (2015).

41. P. Hostert et al., Rapid land use change after socio-economic disturbances: the collapse of the Soviet Union versus Chernobyl. Environ. Res. Lett. 6, 045201 (2011).

15 42. S. Díaz et al., Assessing nature's contributions to people. Science. 359, 270-272 (2018). 43. J. Terborgh et al., in Continental Conservation: Design and Management Principles for Long-term, Regional Conservation Networks, M. E. Soulé, J. Terborgh, Eds. (Island Press, 1999), pp. 39-64.

44. M. E. Soulé, R. Noss, in Complementary Goals for Continental Conservation. (1998), vol. 8 of Wild Earth, pp. 19-28.

45. J.-C. Svenning et al., Science for a wilder Anthropocene: Synthesis and future directions for trophic rewilding research. Proc. Natl. Acad. Sci. 113, 898-906 (2016).

46. wilderness $\mid$ Definition of wilderness in English by Oxford Dictionaries, (available at https://en.oxforddictionaries.com/definition/wilderness).

25 47. R. L. Chapman, Ecological restoration restored. Environ. Values. 15, 463-478 (2006).

48. wildness $\mid$ Definition of wildness in English by Oxford Dictionaries, (available at https://en.oxforddictionaries.com/definition/wildness).

49. J. Bengtsson et al., Reserves, resilience and dynamic landscapes. AMBIO J. Hum. Environ. 32, 389-396 (2003).

30 50. T. Elmqvist et al., Response diversity, ecosystem change, and resilience. Front. Ecol. Environ. 1, 488-494 (2003).

51. K. N. Suding, K. L. Gross, G. R. Houseman, Alternative states and positive feedbacks in restoration ecology. Trends Ecol. Evol. 19, 46-53 (2004).

52. R. V. Sole, M. Montoya, Complexity and fragility in ecological networks. Proc. R. Soc. B 35 Biol. Sci. 268, 2039-2045 (2001).

53. C. N. Foster, P. S. Barton, D. B. Lindenmayer, Effects of large native herbivores on other animals. J. Appl. Ecol. 51, 929-938 (2014).

54. R. van Klink, F. van der Plas, C. G. E. T. van Noordwijk, M. F. WallisDeVries, H. Olff, Effects of large herbivores on grassland arthropod diversity: Large herbivores and arthropods.

$40 \quad$ Biol. Rev. 90, 347-366 (2015).

55. D. H. Janzen, Dispersal of small seeds by big herbivores: Foliage is the fruit. Am. Nat. 123, 338-353 (1984).

56. C. Bello et al., Defaunation affects carbon storage in tropical forests. Sci. Adv. 1, e1501105-e1501105 (2015).

45 57. P. S. Barton, S. A. Cunningham, D. B. Lindenmayer, A. D. Manning, The role of carrion in maintaining biodiversity and ecological processes in terrestrial ecosystems. Oecologia. 171, 
761-772 (2013).

58. R. van Klink, M. F. WallisDeVries, Risks and opportunities of trophic rewilding for arthropod communities. Philos. Trans. R. Soc. B Biol. Sci. 373, 20170441 (2018).

59. W. J. Ripple et al., Status and ecological effects of the World's largest carnivores.

Science. 343, 1241484-1241484 (2014).

60. W. J. Ripple et al., Collapse of the World's largest herbivores. Sci. Adv. 1, e1400103e1400103 (2015).

61. E. S. Bakker et al., Combining paleo-data and modern exclosure experiments to assess the impact of megafauna extinctions on woody vegetation. Proc. Natl. Acad. Sci. 113, 847-855 (2016).

62. M. Cardillo, Multiple causes of high extinction risk in large mammal species. Science. 309, 1239-1241 (2005).

63. R. Dirzo et al., Defaunation in the Anthropocene. Science. 345, 401-406 (2014).

64. I. Dorresteijn et al., Incorporating anthropogenic effects into trophic ecology: Predatorprey interactions in a human-dominated landscape. Proc. R. Soc. B Biol. Sci. 282, 20151602 (2015).

65. D. P. J. Kuijper et al., Paws without claws? Ecological effects of large carnivores in anthropogenic landscapes. Proc. R. Soc. B Biol. Sci. 283, 20161625 (2016).

66. J. A. Dunne, R. J. Williams, N. D. Martinez, Network structure and biodiversity loss in food webs: Robustness increases with connectance. Ecol. Lett. 5, 558-567 (2002).

67. J. Persson, G. R. Rauset, G. Chapron, Paying for an endangered predator leads to population recovery. Conserv. Lett. 8, 345-350 (2015).

68. S. Ceaușu, R. A. Graves, A. K. Killion, J.-C. Svenning, N. H. Carter, Governing tradeoffs in ecosystem services and disservices to achieve human-wildlife coexistence: HumanWildlife Coexistence. Conserv. Biol. (2019), doi:10.1111/cobi.13241.

69. J. F. Franklin et al., Threads of continuity. Conserv. Pract. 1, 8-17 (2000).

70. D. Lindenmayer, S. Thorn, S. Banks, Please do not disturb ecosystems further. Nat. Ecol. Evol. 1 (2017), doi:10.1038/s41559-016-0031.

71. S. Thorn et al., Impacts of salvage logging on biodiversity: A meta-analysis. J. Appl.

30 Ecol. 55, 279-289 (2018).

72. D. Kulakowski et al., A walk on the wild side: Disturbance dynamics and the conservation and management of European mountain forest ecosystems. For. Ecol. Manag. 388, 120-131 (2017).

73. J. Putkunz, in Der Leipziger Auwald - ein dynamischer Lebensraum. Tagungsband zum 5. Leipziger Auensymposium am 16. April 2011, C. Christian, A. Reiher, U. Zäumer, H. D. Kasperidus, Eds. (2011), vol. 06/2011 of UFZ-Bericht, Helmholtz-Zentrum für Umweltforschung, pp. 31-37.

74. K. E. Moseby, G. W. Lollback, C. E. Lynch, Too much of a good thing; successful reintroduction leads to overpopulation in a threatened mammal. Biol. Conserv. 219, 78-88 (2018).

75. T. N. Wasserman, S. A. Cushman, A. S. Shirk, E. L. Landguth, J. S. Littell, Simulating the effects of climate change on population connectivity of American marten (Martes americana) in the northern Rocky Mountains, USA. Landsc. Ecol. 27, 211-225 (2012).

76. R. C. Lacy, Importance of genetic variation to the viability of mammalian populations. $J$. Mammal. 78, 320-335 (1997).

77. J. M. Rey Benayas, J. M. Bullock, in Rewilding European Landscapes, H. M. Pereira, L. 
M. Navarro, Eds. (Springer International Publishing, Cham, 2015; http://link.springer.com/10.1007/978-3-319-12039-3_7), pp. 127-142.

78. T. Merckx, H. M. Pereira, Reshaping agri-environmental subsidies: From marginal farming to large-scale rewilding. Basic Appl. Ecol. 16, 95-103 (2015).

79. A. Cortés-Avizanda, R. Jovani, M. Carrete, J. A. Donázar, Resource unpredictability promotes species diversity and coexistence in an avian scavenger guild: a field experiment. Ecology. 93, 2570-2579 (2012).

80. J. A. Estes et al., Trophic downgrading of planet Earth. Science. 333, 301-306 (2011).

81. F. Berkes, C. Folke, Eds., Linking social and ecological systems: Management practices and social mechanisms for building resilience (Cambridge Univ. Press, Cambridge, Transferred to digital printing., 1998).

82. G. C. Daily, Ed., Nature's services: societal dependence on natural ecosystems (Island Press, Washington, DC, Nachdr., 1997).

83. S. Díaz et al., The IPBES Conceptual Framework - connecting nature and people. Curr. Opin. Environ. Sustain. 14, 1-16 (2015).

84. L. M. Fredrickson, D. H. Anderson, A qualitative exploration of the wilderness experience as a source of spiritual inspiration. J. Environ. Psychol. 19, 21-39 (1999).

85. I. Markevych et al., Exploring pathways linking greenspace to health: Theoretical and methodological guidance. Environ. Res. 158, 301-317 (2017).

20 86. K. Engemann et al., Childhood exposure to green space - A novel risk-decreasing mechanism for schizophrenia? Schizophr. Res. (2018), doi:10.1016/j.schres.2018.03.026.

87. A. S. Masten, M. J. Reed, in Handbook of positive psychology, S. J. Lopez, C. R. Snyder, Eds. (Oxford Univ. Press, Oxford, 1. issued as paperback, 2. ed., 2005), Oxford library of psychology, pp. 74-88; 6.

25 88. L. Naor, O. Mayseless, How personal transformation occurs following a single peak experience in nature: A phenomenological account. J. Humanist. Psychol., 002216781771469 (2017).

89. J. V. Krutilla, Conservation reconsidered. Am. Econ. Rev. 57, 777-786 (1967).

90. R. R. Alexander, Modelling species extinction: The case for non-consumptive values.

30 Ecol. Econ. 35, 259-269 (2000).

91. R. T. Corlett, The role of rewilding in landscape design for conservation. Curr. Landsc. Ecol. Rep. 1, 127-133 (2016).

92. J. C. Jobse, L. Witteveen, J. Santegoets, D. J. Stobbelaar, in Rewilding European Landscapes, H. M. Pereira, L. M. Navarro, Eds. (Springer International Publishing, Cham, 2015; http://link.springer.com/10.1007/978-3-319-12039-3_10), pp. 191-204.

93. L. H. Gunderson, in Navigating social-ecological systems: Building resilience for complexity and change., F. Berkes, J. Colding, C. Folke, Eds. (Cambridge University Press, Cambridge UK, 2003).

94. "The IUCN Programme 2013 - 2016" (IUCN, Gland, 2012).

40 95. M. G. Turner, Disturbance and landscape dynamics in a changing world. Ecology. 91, 2833-2849 (2010).

96. N. Bauer, A. Wallner, M. Hunziker, The change of European landscapes: Human-nature relationships, public attitudes towards rewilding, and the implications for landscape management in Switzerland. J. Environ. Manage. 90, 2910-2920 (2009).

45 97. A. Treves, in Wildlife and society: the science of human dimensions (Island Press, Washington, D.C., 2009). 
98. J. Fischer, T. Hartel, T. Kuemmerle, Conservation policy in traditional farming landscapes: Conserving traditional farming landscapes. Conserv. Lett. 5, 167-175 (2012).

99. T. Plieninger et al., Exploring ecosystem-change and society through a landscape lens: Recent progress in European landscape research. Ecol. Soc. 20 (2015), doi:10.5751/ES-07443200205.

100. U. Schirpke, F. Timmermann, U. Tappeiner, E. Tasser, Cultural ecosystem services of mountain regions: Modelling the aesthetic value. Ecol. Indic. 69, 78-90 (2016).

101. F. Höchtl, S. Lehringer, W. Konold, "Wilderness": what it means when it becomes a reality - a case study from the southwestern Alps. Landsc. Urban Plan. 70, 85-95 (2005).

102. K. Arts, A. Fischer, R. Van der Wal, The promise of wilderness between paradise and hell: A cultural-historical exploration of a dutch National Park. Landsc. Res. 37, 239-256 (2012).

103. C. R. Margules, R. L. Pressey, Systematic conservation planning. Nature. 405, 243-253 (2000).

104. R. H. Green, Sampling design and statistical methods for environmental biologists (Wiley, New York, NY, 1979), A Wiley-Interscience publication.

105. D. Haase, J. Gläser, Determinants of floodplain forest development illustrated by the example of the floodplain forest in the District of Leipzig. For. Ecol. Manag. 258, 887-894 (2009).

106. K. Richter, H. Teubert, in Der Leipziger Auwald - ein dynamischer Lebensraum. Tagungsband zum 5. Leipziger Auensymposium am 16. April 2011, C. Wirth, A. Reiher, U. Zäumer, H. D. Kasperidus, Eds. (2011), vol. 06/2011 of UFZ-Bericht, Helmholtz-Zentrum für Umweltforschung, pp. 45-50.

107. Lebendige Luppe - Sozialwissenschaftliche Begleitung, (available at https://lebendigeluppe.de/index.php?article_id=19). 108. 1904-1914 - Swiss National Parc. https://www.nationalpark.ch/en/about/aboutus/foundation-and-development/1904-1914/

109. H. Lozza, in Jahrbuch des Vereins zum Schutz der Bergwelt (München, 2014), vol. 79. Jahrgang, pp. 69-78.

110. Bundesversammlung der Schweizerischen Eidgenossenschaft, Bundesgesetz über den Schweizerischen Nationalpark im Kanton Graubünden (Nationalparkgesetz) (1980).

111. J. Senn, W. Suter, Ungulate browsing on silver fir (Abies alba) in the Swiss Alps: Beliefs in search of supporting data. For. Ecol. Manag. 181, 151-164 (2003).

112. M. Schütz, A. C. Risch, E. Leuzinger, B. O. Krüsi, G. Achermann, Impact of herbivory by red deer (Cervus elaphus L.) on patterns and processes in subalpine grasslands in the Swiss National Park. For. Ecol. Manag. 181, 177-188 (2003).

113. Backhaus N., C. Buser, M. Adamec, D. Jorio, M. Speich, Wirtschaftliche Auswirkungen des Sommertourismus im UNESCO Biosphärenreservat Val Müstair Parc Naziunal. Schriftenreihe Humangeographie. 27 (2013).

40 Bern, 2014).

115. M. Galetti, A. S. Pires, P. H. S. Brancalion, F. A. S. Fernandez, Reversing defaunation by trophic rewilding in empty forests. Biotropica. 49, 5-8 (2017).

116. F. A. S. Fernandez et al., Rewilding the Atlantic Forest: Restoring the fauna and ecological interactions of a protected area. Perspect. Ecol. Conserv. 15, 308-314 (2017).

117. P. A. Jansen et al., Thieving rodents as substitute dispersers of megafaunal seeds. Proc. Natl. Acad. Sci. 109, 12610-12615 (2012). 
118. E. Nichols et al., Ecological functions and ecosystem services provided by Scarabaeinae dung beetles. Biol. Conserv. 141, 1461-1474 (2008).

119. E. Viveiros de Castro, T. Beraldo Souza, B. Thapa, Determinants of Tourism Attractiveness in the National Parks of Brazil. Parks. 21, 51-62 (2015). 120. M. M. Carreiro, W. C. Zipperer, Co-adapting societal and ecological interactions following large disturbances in urban park woodlands: Disturbance effects in urban parks. Austral Ecol. 36, 904-915 (2011).

121. J.-P. Briot, P. Guyot, M. Irving, F. Barros, N. Frydman, N. Giambasi, B. Zeigler, Eds. (The Society for Modeling \& Simulation International (SCS), Buenos Aires, 2007).

122. O. A. Barros, M. E. Melo, From Myth to Reality: The Experience of Sustainable Tourism in The Vale Encantado Community in Tijuca Forest, Rio de Janeiro, Brazil. Field Actions Sci. Rep. J. Field Actions (2011).

123. A. Nidumolu, Vale Encantado: An Emerging Example for Sustainable Communities. RioOnWatch - Community Report. Rio (2015).

15 124. A. Moller, T. Mousseau, Biological consequences of Chernobyl: 20 years on. Trends Ecol. Evol. 21, 200-207 (2006).

125. "Environmental Consequences of the Chernobyl Accident and Their Remediation: Twenty Years of Experience," Radiological Assessment Reports Series (International Atomic Energy Agency (IAEA), Vienna, 2006).

20 126. K. Baverstock, Chernobyl: An Overlooked Aspect? Science. 299, 44b - 44 (2003).

127. http://www.zapovednik.by/en/about/. http://www.zapovednik.by/en/about/.

128. http://chornobyl-gef.com/en/tasks-of-the-reserve.html. Httpchornobyl-Gefcomentasks--Reserv.

129. A. Torres et al., Measuring rewilding progress. Philos. Trans. R. Soc. B Biol. Sci. (2018), doi:10.1098/rstb.2017.0433.

130. N. Pettorelli et al., Making rewilding fit for policy. J. Appl. Ecol. (2018), doi:10.1111/1365-2664.13082.

131. L. M. Navarro, H. M. Pereira, in Rewilding European Landscapes, H. M. Pereira, L. M. Navarro, Eds. (Springer International Publishing, Cham, 2015;

30 http://link.springer.com/10.1007/978-3-319-12039-3_11), pp. 205-223.

132. Ministerio de Medio Ambiente y Recursos Naturales (MARN), UN Decade of Ecosystem Restoration 2021 - 2030 Initiative proposed by El Salvador with the support of countries from the Central American Integration System (SICA) - Concept Note (2018), (available at http://hdl.handle.net/20.500.11822/26027).

35 133. Scenarios for the 2050 vision for biodiversity (Convention of Biological Diversity (CBD), Montreal, Canada, 2010).

134. G. M. Mace et al., Aiming higher to bend the curve of biodiversity loss. Nat. Sustain. 1, 448-451 (2018).

40 Acknowledgments: AP thanks Melissa Marselle, Isabel Rosa, Aurora Torres, Carsten Meyer and Jes Hines for valuable comments on earlier drafts of this manuscript, and three anonymous reviewers whose comments helped to improve this work substantially. 
Funding: AP, HMP, LMN, GP, RvK and NF are supported by the German Centre for integrative Biodiversity Research (iDiv) Halle-Jena-Leipzig, funded by the German Research Foundation (FZT 118). JCS and SC thank the Carlsberg Foundation (Semper Ardens project MegaPast2Future, grant CF16-0005 to JCS) and the VILLUM FONDEN (VILLUM Investigator project, grant 16549 to JCS) for economic support. AL was supported by the Portuguese Science and Technology Foundation (FCT) through Grant SFRH/BPD/80747/2011 and FARSYD project. ACA was supported by a post-doctoral contract Juan de la Cierva Incorporación (IJCI-2014- 20744) of the Spanish Ministry of Economy and Competitiveness and by a post-doctoral of the Vicepresidencia y Consejería de Innovación, Investigación y Turismo of the Govern de les Illes Balears (PD/039/2017). JMB acknowledges funding from CEH NC project NEC06895. JMRB was supported by the Spanish Ministry of Economy and Competitiveness (grant number CGL201453308-P) and the Madrid Government (project S2013/MAE-2719 REMEDINAL-3).

Author contributions: The ideas for this paper were developed during a workshop held at the German Centre for Integrative Biodiversity Research, Halle-Jena-Leipzig (iDiv) in Leipzig in November 2016. LMN, HMP and AP coordinated the project. AP and HMP wrote the manuscript with contributions from all authors. LMN and AP designed the figures with input from all authors.

20 Competing interests: Authors declare no competing interests. 


\section{Figure captions:}

\section{Fig. 0. Rewilding actions and outcomes are framed by the societal and the ecological context:}

Rewilding can be assessed by representing the state of ecosystems in a three-dimensional space where each dimension corresponds to an ecological process. Restoration of these processes can positively influence their interactions, e.g., species diversity and trophic complexity can be increased if dispersal to new ecosystems is possible. The difference in volume between the restored (yellow pyramid) and the degraded ecosystem (red pyramid) is a proxy for the effects of rewilding on the self-sustainability of the ecosystem. The dashed line around the yellow pyramid represents the societal boundaries that determine to what extent ecological processes can be restored.

10 Rewilding actions can help to push the societal boundaries further towards the ecological potential (orange arrows), by promoting societal support and opportunities for people to experience the autonomy of ecological processes in enjoyable ways. Societal outcomes can be assessed by mapping positive and negative impacts on non-material, regulating and material contributions from nature (bar plot, right panel). 


\section{Science \\ MAAAS}

\section{Submitted Manuscript: Confidential}

Fig. 1. Promoting interactions among ecosystem processes enhances resilience of rewilding areas. A) Intensively managed areas, are often characterized by decreased trophic complexity. Dispersal barriers between ecosystems impede the movement of individuals, particularly at higher 5 trophic levels. Natural disturbances are often suppressed or altered in their magnitude and frequency, potentially leading to even larger disturbance events. Impoverished trophic networks, dispersal barriers and deterministic disturbances can hamper recovery of depressed populations (open nodes in the trophic webs) after major disturbance events. B) Rewilded areas have restored complex trophic webs, with functional roles of top predators (red nodes) and herbivores (yellow

10 nodes). Improved connectivity among habitats allows for dispersal of species at all trophic levels. Frequent disturbance events occur in the landscape. Dispersal among habitats aids recovery of ecosystems after disturbance events by allowing recolonization and recovery of populations of affected species. Large vertebrates present in complex ecosystems often act as dispersal agents for plants and can introduce stochasticity into a system, e.g. through predation or grazing. 


\section{Science}

MAAAS

\section{Submitted Manuscript: Confidential}

Fig. 2.: Restored ecological processes and their influence on contributions from nature. The ecological state of each case study is represented in a three-dimensional space with one axis for each ecological process of our framework (trophic complexity, dispersal, and stochastic

5 disturbances). The initial ecological state is represented by the red pyramids while the yellow pyramids represent the ecological state after the rewilding actions. The barplots indicate the number of contributions to people (42) that are positively or negatively affected by rewilding actions. (A) Rewetting of a river branch in the Leipziger Auwald led to increases in flood-tolerant species and an overall increase in species richness in several taxa. Management actions increased

10 the provision of non-material (e.g., opportunities for learning and inspiration) and regulating services (e.g., habitat creation and maintenance). Impacts on material services are negligible as the project neither affects large agricultural areas nor significantly improves nature-based income opportunities. (B) Non-management, a hunting-ban and reintroductions improved trophic complexity and stochastic disturbance in the Swiss National Park. Management actions promoted

15 economic prosperity of the region (positive material contributions) and agricultural abandonment (negative material contributions). The park provides non-material and regulating contributions, e.g., opportunities for nature experiences, and habitat creation and maintenance. (C) Reintroductions of mammals to Tijuca National Park improved ecological interactions. Restoration potential of all three processes is limited due to the urban location of the park.

20 Management actions may increase material contributions (i.e. income generation through ecotourism). Non-material contributions, e.g., supporting identities or maintenance of options can potentially emerge from community based projects. (D) Land abandonment, protection and reintroductions led to the recovery of the large mammal community in the Chernobyl exclusion 
zone. Positive regulating, non-material and material contributions include habitat creation and maintenance, opportunities for learning and inspiration, and for wildlife tourism.

(Picture credits: A) pxhere creative commons license CC00, B) pxhere creative commons license CC00, C) Brian Gratwicke/Wikimedia Commons, D) Max/Adobe Stock) 
Science

Figure 0:

5

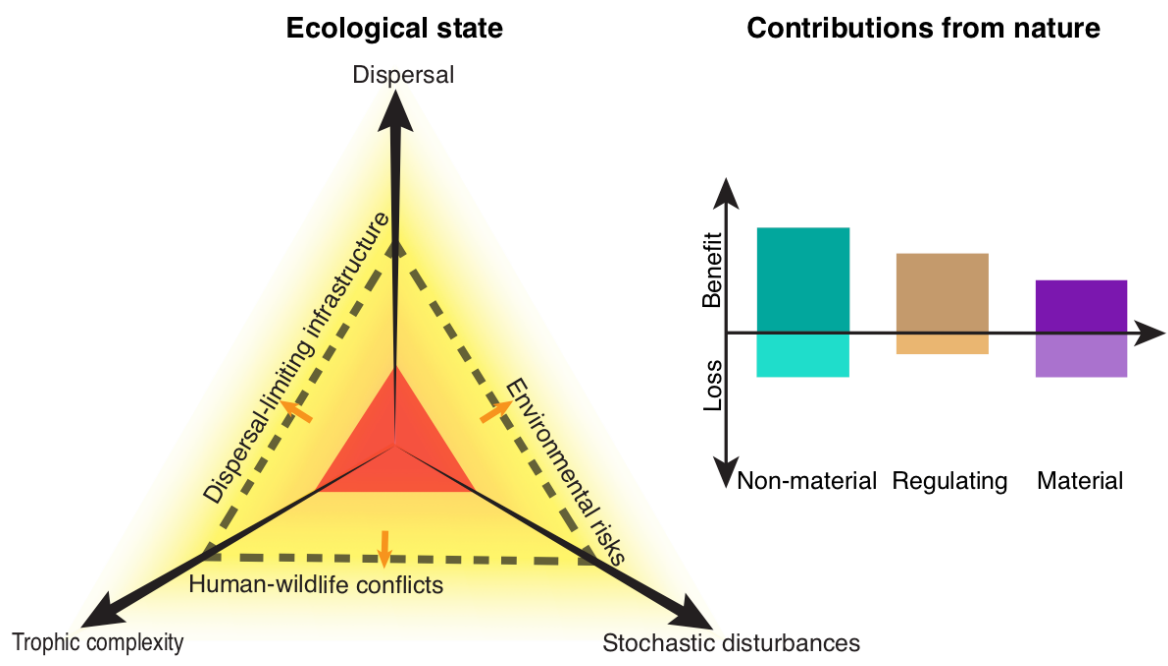


DAAAS

Figure 1:

5

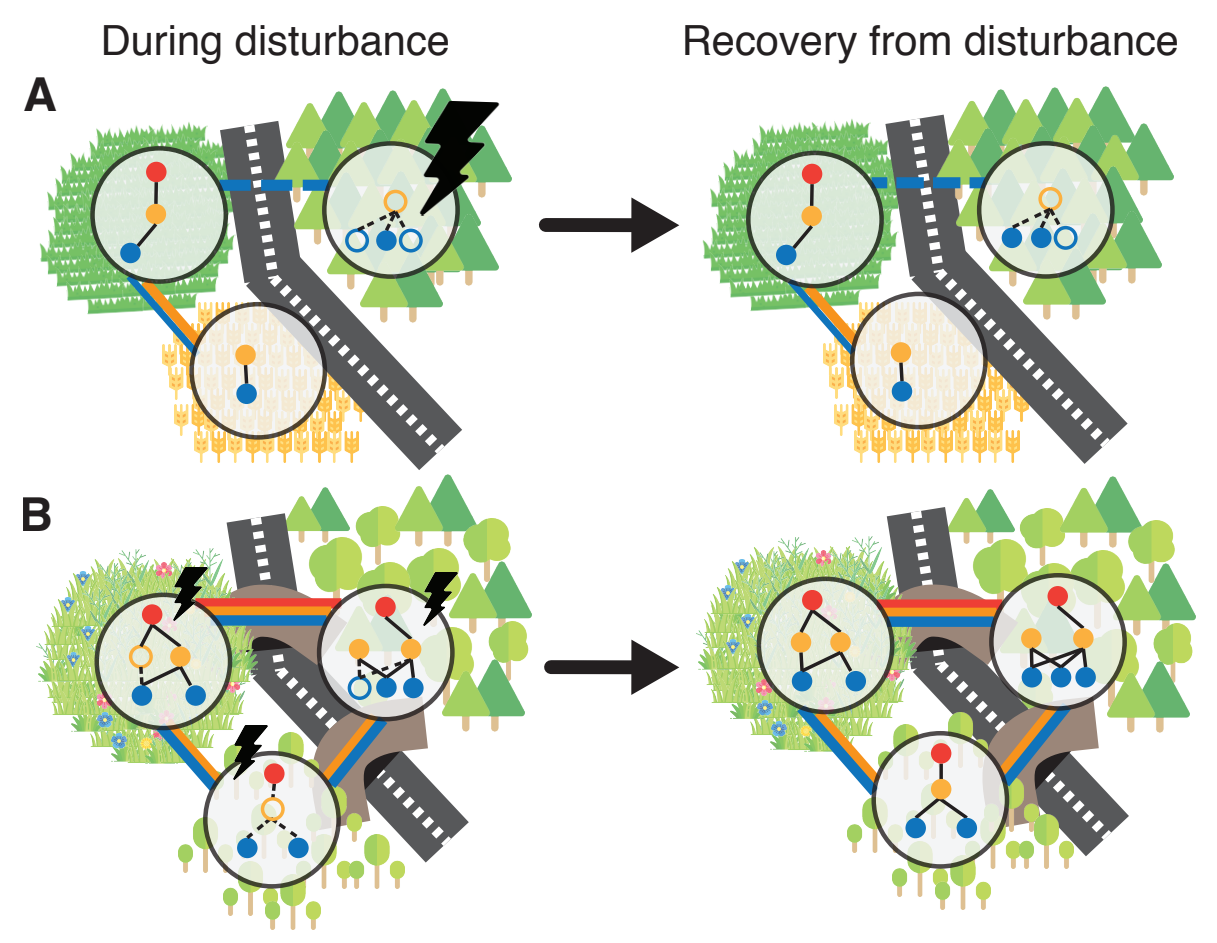

Legend

3 Disturbance ( ) 
Figure 2:
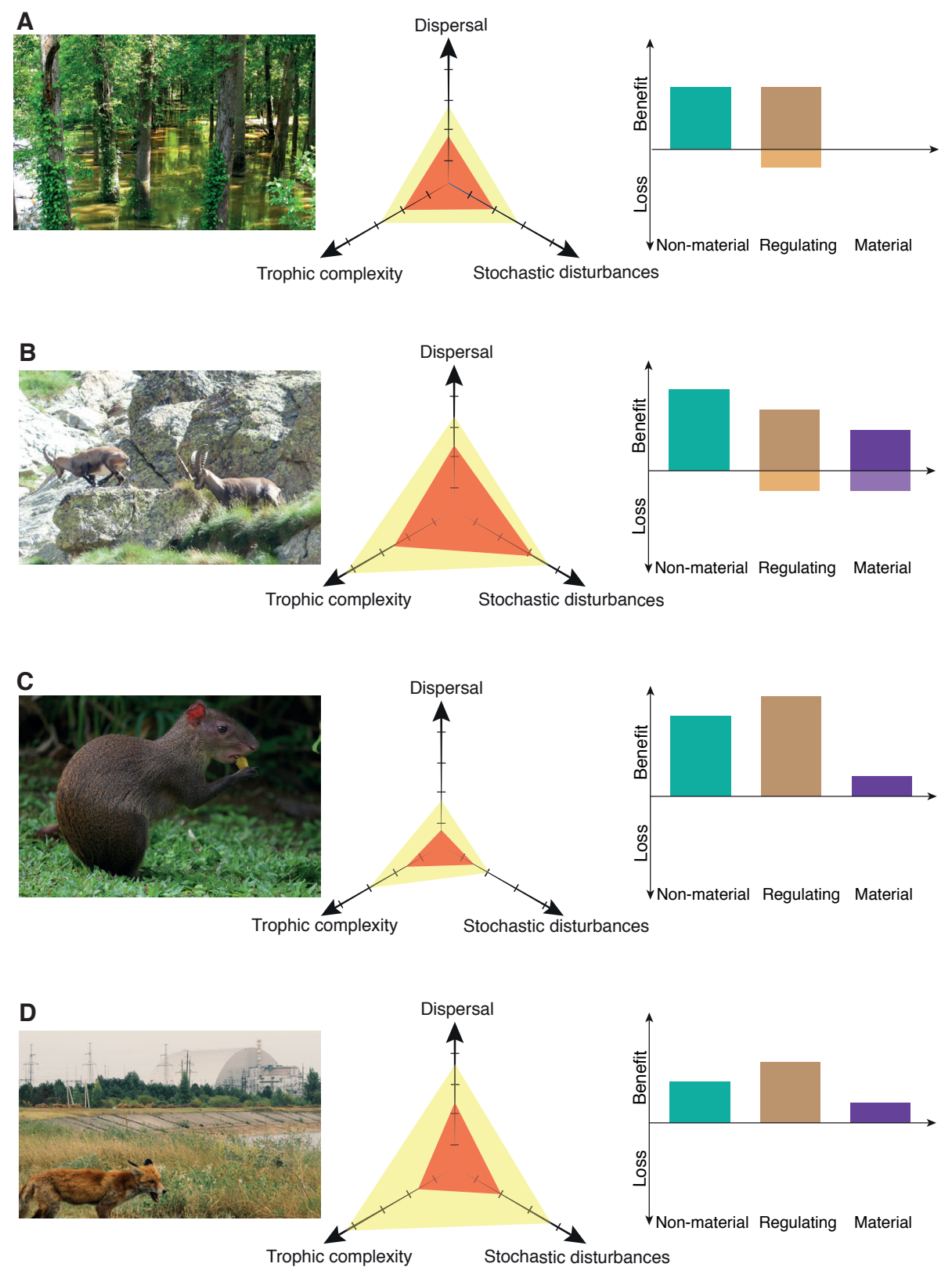